\author{
Educational Research for Social Change (ERSC) \\ Volume 9 No. 2 September 2020
}

pp. $65-80$

ersc.nmmu.ac.za

ISSN: 2221-4070

\title{
Using Collages to Change School Governing Body Perceptions of Male Foundation Phase Teachers ${ }^{1}$
}

\author{
Obakeng Kagola \\ Nelson Mandela University \\ obakengk@mandela.ac.za \\ Mathabo Khau \\ Nelson Mandela University \\ Mathabo.khau@mandela.ac.za
}

\begin{abstract}
The paper explores how collages can be used to change school governing body (SGB) members' perceptions of male teachers in the foundation phase (FP) in the Nelson Mandela Metropole, South Africa. The involvement of men in FP teaching forms part of initiatives to diversify and do away with the underrepresentation of men in the early years of learning. SGBs play an integral role in the recruitment and retaining of teachers in schools, but not much is known on how SGBs perceive male teachers and their willingness to employ them in FP. This study involved parent members of SGBs as participants because they represent the majority membership in primary school governance. This qualitative study was underpinned by feminist post-structural theory as a lens to analyse data generated using collages and a group discussion, both of which were later thematically analysed to generate the themes discussed in this paper. Findings indicate that participants' socialisation and lived experiences play a major role in the employment of teachers in FP. The findings also show that engaging in participatory visual methodologies such as collages can provide a platform for transformation of deeply embedded discourses towards equitable and socially just societies. In understanding that change is a process, the study recommends that participatory visual methodologies be used in courageous conversations with communities about constructions of caring masculinities and the involvement of men in care professions such as FP teaching.
\end{abstract}

Keywords: collages, feminist post-structural theory, male foundation phase teachers, school governing body

Copyright: (C) 2020 Kagola \& Khau.

This is an open access article distributed under the terms of the Creative Commons Attribution NonCommercial License, which permits unrestricted non-commercial use, distribution, and reproduction in any medium, provided the original author and source are credited.

\footnotetext{
${ }^{1}$ Ethical clearance number: H18-EDU-ERE-015
} 
Please reference as: Kagola, O. \& Khau, M. (2020). Using Collages to Change School Governing

Body Perceptions of Male Foundation Phase Teachers. Educational Research for Social

Change, 9(2), 65-80. http://dx.doi.org/10.17159/2221-4070/2020/v9i2a5

\section{Background and Introduction}

The effort to recruit and retain male foundation phase (FP) teachers is a global phenomenon (Brownhill, 2016; Moosa \& Bhana, 2018; Skelton, 2012; Warin, 2019). The aim of recruiting men in FP is to counteract the underrepresentation of men in this educational phase, and to work towards gender balance in FP teaching and learning. The effort also aims to disrupt the normalised patriarchal division of labour that positions FP teaching as women's work (Bhana, 2016; Cushman, 2008; Msiza, 2019). According to Brownhill (2016), recruiting men in FP teaching can contribute to the development of fair and equal gender order in society and the labour market. Cushman $(2005,2008)$ further asserted that employing both female and male teachers in FP may shift the perception of FP being women's work and thus not a commendable profession for men. Warin (2019) explained that having both male and female teachers enables children to experience the different approaches to teaching and interpersonal relations that the different genders bring, and enables them to explore both their feminine and masculine sides. This experience provides them with a frame of reference about the different ways of being boys and girls. According to Moosa and Bhana (2018), Ratele (2015), and Xu and Waniganayake (2018), the involvement of men in care professions including FP teaching helps to deconstruct patriarchal, normative, and toxic masculinities characterised by aggression. It creates opportunities for reconstructing masculinities that are grounded in caring and nurturing behaviour.

The inclusion of men in FP teaching is a positive move towards equitable social practices to diversify this educational phase and disrupt the gendered perception of FP teaching (Moosa \& Bhana, 2018; Msiza, 2019). It further encourages conversations with communities and stakeholders involved in school governance about the need for involving men in care professions such as FP teaching. This study aims to contribute to the ongoing conversation of constructing different forms of masculinity that are caring and possibly pro-feminism (Ratele, 2015).

School governing bodies (SGBs) in South Africa have the responsibility of recommending the employment of teachers and administrative staff in schools (Republic of South Africa, 2011a). This responsibility contributes to the recruitment, retention, and diversification of teachers in all educational phases. It therefore becomes imperative to understand the power that SGBs possess, and how they perceive employing male teachers in FP. By examining the power relations in schools in the Eastern Cape province of South Africa, we gained an understanding of how the gendered social order is regulated, structured, and sustained in FP teaching as a discourse (Blaise, 2005; Weedon, 2004). Such an understanding is a starting point for positive change.

In South Africa, equal distribution of labour has been a priority since the dawn of democratic rule in 1994 (Republic of South Africa, 2011b). The purpose was to redress injustices of the past in all government departments, including education. The redistribution was done in the form of policy implementation in the Department of Education (DoE) where the South African Schools Act (SASA) of 1996 was adopted (Republic of South Africa, 2011a). The creation of multi-stakeholder involvement through the implementation of SGBs was aimed at decentralising school governance. The multistakeholder participation in the governance of schools includes school principals, teachers, administrative staff members, parents, and learners in the case of secondary schools (Republic of South Africa, 2011a). In primary schools, parents of learners form the majority in the governance committee (Republic of South Africa, 2011a). The SASA provides SGBs with powers to recommend the employment of teachers and administrative staff in schools and to oversee financial management and disciplinary action against staff members and learners (Mncube, 2009; Republic of South Africa, 
2011a). SGBs are further obligated to advance social justice and promote democratic values in schools through the employment of staff in a nondiscriminatory way (Mncube \& Mafora, 2013; Republic of South Africa, 2011a).

Yet, two decades after implementation of the SASA, and initiatives to recruit men to teach in the FP, there has not been a significant improvement in South Africa. FP teaching remains dominated by female teachers. Statistics indicate that only $22.7 \%$ of teachers in FP are male (SNAP, 2015 as cited in Bhana, 2016). Researchers have investigated why this is the case by exploring the views of teachers and students enrolled in teacher education programmes (Bhana, 2016; Mashiya et al., 2015; Moosa \& Bhana 2018; Msiza, 2019). However, not much is known about how SGBs perceive men teaching in FP.

The Eastern Cape, in particular, has been underresearched regarding the phenomenon of male FP teachers, and how those in school governance perceive them. Working with SGBs to redress the gendered distribution of labour in the Eastern Cape is a positive move towards the employment of more men in FP. Furthermore, the findings could help SGBs, teachers, and, ultimately, learners to rethink and construct a different form of masculinity-one that positions men as caring and nurturing. This participatory study contributes to the conscientisation of SGBs with respect to their responsibility to promote diversity and equitable work opportunities for all in the professionalisation of FP teaching.

\section{Foundation Phase Teaching as a Gendered Space}

According to Mashiya et al. (2015), Skelton (2012), as well as Unterhalter and North (2011), social values, norms, and cultural stereotypes associated with gender roles in different contexts perpetuate gender bias towards men interested in teaching young children or in any profession categorised as care work. Gender continues to be the determining factor in the division and valuing of labour (Moosa \& Bhana, 2018; Connell, 2012). Work that incorporates nurturing and care is devalued and regarded as work that undermines men's intelligence and their social standing in society. While it is socially acceptable for women to cross the gender border and pursue previously male professions such as engineering and construction work, it is difficult for men to access and fully participate in care professions without being policed by those in authority (Bhana \& Moosa, 2016; Msiza, 2019). Bhana and Moosa $(2016$, p. 1) suggested that the rationale behind the encouragement of women to pursue previously male professions is premised on creating "gender-sensitive policies."

The Eastern Cape is known for the rich culture of the amaXhosa, which has certain practices and norms (Mfecane, 2016; Ntombana, 2011; Tenge, 2006). These include taking boy children through the traditional initiation rite of passage (ulwaluko) and instruction on gendered roles associated with being a man such as choosing hard labour and not care work. For men in patriarchal societies such as the amaXhosa, the work they do is a major contributor to their construction of masculinity and positioning in the societal ranks of the community (Mashiya et al., 2015; Ratele, 2015). Men working in caring professions are normally positioned in the subordinate masculinities because of the low value and remuneration of the work. In the amaXhosa culture, these men are perceived as being weak and incapable of providing for their families and therefore, not able to fulfil the role of provider and head of the family (Mfecane, 2016; Msiza, 2019). The DoE is one government department that has not changed much regarding the employment of more men in the gendered care work of teaching young children (Bhana, 2016; Petersen, 2014). This is evident particularly in areas that still have a patriarchal and hegemonic conceptualisation of what a man should be, look like, and how he should act. The underrepresentation of men leads to the assumption that when SGBs recommend employment in this educational phase, their decision is based on gender roles-care work is women's work (Bhana, 2009; Mashiya et al., 2015). 
In a bid to address the gender divide in care work generally and FP teaching specifically, it is important to reconstruct masculinities in communities (Moosa \& Bhana, 2020; Msiza, 2020). Therefore, involving men to teach in FP or in any other care work creates a space to reconstruct a different form of masculinity that is softer, gentler, and more caring rather than perpetuating stereotypic gender roles (Moosa \& Bhana, 2018). According to Bhana (2016), hegemonic ways of thinking have constructed FP teachers to be caring and nurturing mothers. The discourse of FP teachers as mothers resonates with gender roles that have conceptualised what constitutes women's work. This conceptualisation has been a powerful tool in restricting and justifying FP teaching as a female territory (Moosa \& Bhana, 2018). SGB members need to be conscientised about the gendered practices that perpetuate binaries that marginalise women and men in opportunities of employment in schools.

Karlsson (2002) recommended that measures to prevent a reenactment of traditional stereotypes of race, class, and gender inequalities are needed for transformation and the realisation of equality in education. SGBs are members of the broader community in which they live. Thus, there are social values, norms, and cultural stereotypes that these members represent in their task of governing schools. Moreover, SGBs may be unaware of the gendered school practice that exists regarding differentiated opportunities in employment and the implementation of policies in education (Blee \& Tickamyer, 1995, cited in Mashiya et al., 2015).

\section{Theoretical Perspectives: A Feminist Post-structural Lens}

The feminist post-structural theory was adopted to understand the perceptions of SGB members in relation to male FP teachers in the context of Eastern Cape schools (Osgood, 2012; Pitsoe \& Letseka, 2013; Weedon, 2004). This theory was adopted because it acknowledges that shared discourses or cultural histories are socially constructed, and that dominant discourses can trap us in conventional meanings and modes of being (Davies, 1999; Gough \& Whitehouse, 2003). Furthermore, feminist poststructuralism works towards gaining an understanding of the ways we understand ourselves. It questions the legitimacy of our perceptions and it brings previously marginalised discourses to the forefront (Burr, 1995). This means one needs to recognise that research participants may be from a Xhosa patriarchal discourse that still regards care work as women's work, despite the evolving and changing society.

Gough and Whitehouse (2003) argued that discourse intersects with language. Through language practices, discourses, shared cultural practices, and cultural narratives are produced (Carabine, 2001; Osgood, 2012) that are socially, historically, and institutionally specific structures of categories, beliefs, statements, and terms (Carabine, 2001; Osgood, 2012; Scott, 1988). For example, Moosa and Bhana (2018) argued that these beliefs and institutional categorisations have continually been used to justify perceptions and to keep men away from teaching in the FP. And, Pitsoe and Letseka (2013, p. 23) suggested that "discourse, as a social construct, is created and perpetuated by those who have the power and means of communication." So, using the present research focus, those who are in control decide that women should teach in the FP because of an associated assumption that women are better at caring and are more nurturing than men. Yet, FP teaching is a profession like any other and should be recognised as such - just as in other educational bands.

In a social context, people have different subjectivities towards a discourse that allows individuals to position themselves in different ways (Barrett, 2005). Weedon (1997) agreed with Foucault (1978) that knowledge is constructed through discourses, which, together with social practices, form power relations and subjectivity. Using this theoretical underpinning helped with the interpretation and critical analysis of the data generated with SGB members. Adopting feminist post-structural theory 
enabled us to understand how language is used to categorise people and marginalise those who do not fit the stereotype of the FP teacher.

\section{Participatory Methodologies: Encouraging Conversations Through Collages}

The study is located in the qualitative research approach that allows the participants to share their viewpoints and lived experiences (Creswell, 2013a). Merriam (2009) posited that qualitative research is about exploring people's perceptions, interpretations, and meanings in a context. This study aimed to explore how SGB members perceive FP male teachers in the context of the Nelson Mandela Bay Metropolitan district of the Eastern Cape. The Eastern Cape is a diverse province dominated by rural communities and contains a range of South African cultural and tribal groups, including those of the Xhosa, English, Afrikaners, Zulus, Basotho, and Batswana people. However, the dominant cultural group is that of the amaXhosa, which has its own values, norms, and practices.

The critical paradigm was selected for the study because it aligns with the aims of the methodology, which is to raise consciousness as well as disrupt unjust norms in societies (Taylor \& Medina, 2013). Moreover, researchers from the critical paradigm consider the research process to be an intervention whereby participants identify a problem and view themselves as part of the solution (Ponterotto, 2005; Taylor \& Medina, 2013). A participatory visual research methodology (PVRM) was adopted as the design and a participatory visual strategy of collage making was adopted as the method of data generation. According to de Lange et al. (2013) and Mitchell and de Lange (2013), PVRM enables participants to make visible what is known to them and, in the process, reflect on their knowledge and experience, enabling them to de- and reconstruct their understanding of the phenomenon in question. Ostby (2017), in her description of what a collage means, posits that it is the process of using fragments of paper images or any other materials and pasting them onto a flat surface to portray a phenomenon. The results of this study were generated from collages and their meanings in the participants' view. Furthermore, we led a collage exhibition and conversations with the participants where participants explained to each other, and assessed each collage and its meaning.

Therefore, the PVRM and the critical paradigm created a space for us to engage in the research process and to actively converse about how the participants perceived male teachers in FP teaching. The study was approved by the Nelson Mandela University ethics committee and permission was obtained from the Eastern Cape provincial DoE. Five primary schools around the area of Missionvale and Zwide in the Nelson Mandela metropole were invited to participate in the study; only two schools accepted the invitation - the others were unable to participate because of reasons beyond their control. Permission was sought from the two school principals to approach the parent members of the SGB. The parent members were purposively selected because they comprise the majority and hold influential positions in the committee such as chairperson and treasurer. Written consent forms were read and explained to the participants. Permission to record the collage making conversations was obtained from participants in writing. Pseudonyms were used throughout the study to ensure anonymity. To allow the generation of rich data, participants were given the freedom to use the language of their choice in the presentations and discussions. All participants used isiXhosa. We gave the participants the following collage prompt: "Create a collage showing your ideal foundation phase teacher."

One strength of PVRM is that because participants present and engage with each other's collages and what they mean, they are already involved in the first layer of analysing the data (de Lange et al., 2006). We made notes of the common issues raised by the participants as they engaged with each other's collage presentations. Before the presentations, we gave them the following questions to think about as others presented their collages: 
- What do we see?

- What does it mean?

- What is missing from the collages?

The above questions helped participants to critically reflect on their understanding of what positive attributes an FP teacher should have, irrespective of their gender and sexuality. We later thematically analysed the data generated through collage making, guided by Tesch's steps, as mentioned by Creswell (2013b). These steps included transcribing and translating isiXhosa conversations to English. After transcription and translation, we took note of the first layer of data analysis, which participants were involved in given that they were engaging with the above questions. We further repeatedly read the transcribed data in search of common themes. The themes were then coded and codes were written next to the relevant paragraphs of the text. The most descriptive categories were identified, and all related themes were condensed into these categories. To ensure the accuracy and quality of the findings, we went back to the original data generated in isiXhosa and regularly checked consistency in data and themes. We also did member checking with the participants where we did not understand, or needed clarity on, the data to make sure that the integrity and trustworthiness of the study was maintained.

\section{Findings and Discussions}

We begin our findings by presenting collages made by the SGB parent component member participants. These are followed by extracts from the conversations participants had during the collage making process and exhibition. In Table 1, are the collages with, next to each, the participants' views on what they mean. During the exhibition of collages, participants shared their reflections on what they saw in each collage, what it meant, and what was missing from the collages. 
Table 1

SGB Member Collages and Their Meanings
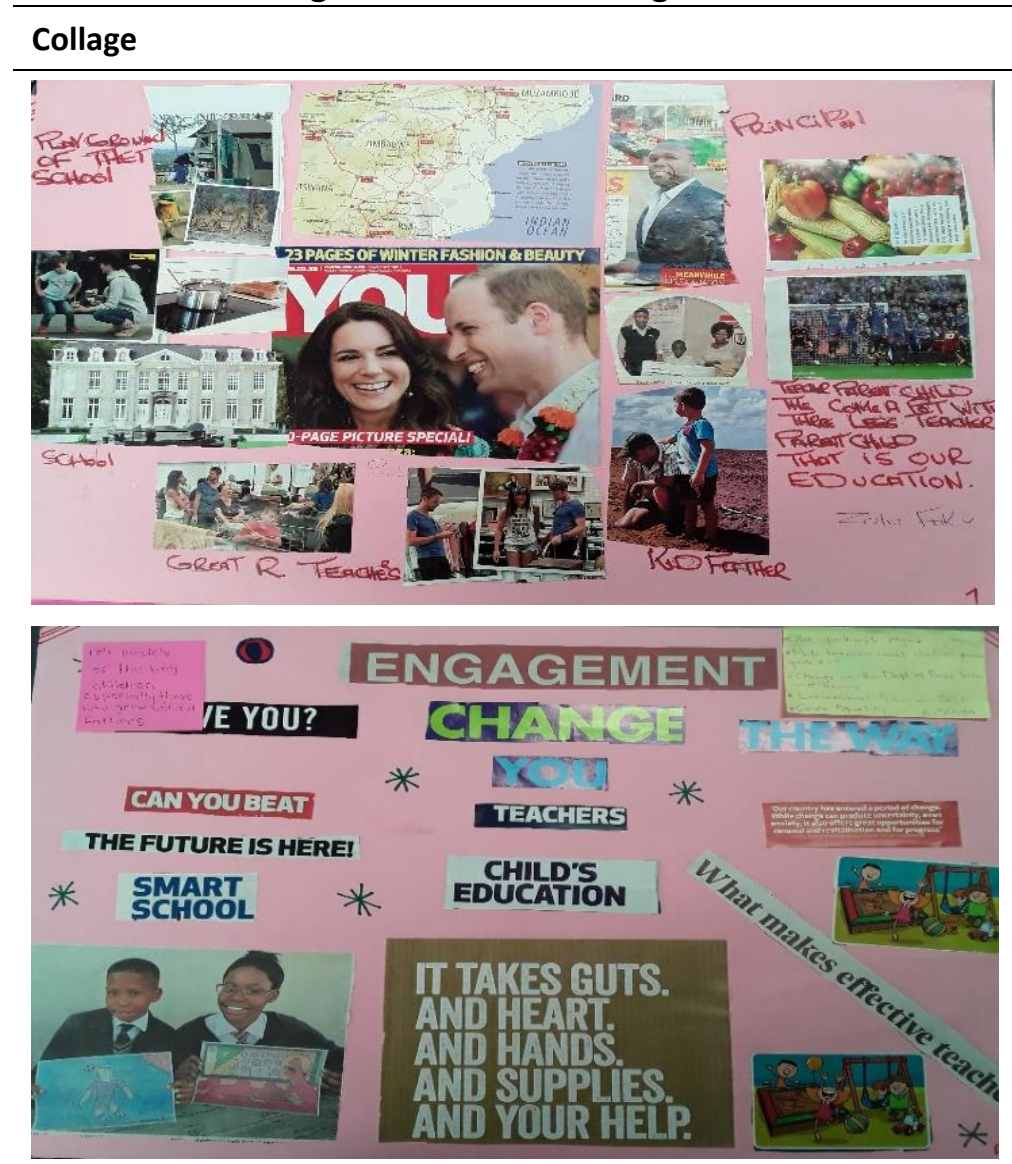

What do the collages mean?
My ideal foundation phase teacher is a woman because it is their responsibility and it is in their nature to take care of children. Today in schools, we are worried about the safety of the learners, certain male teachers molest children and they do not have the patience to deal with them, and this is a current problem, so men cannot teach in foundation phase. (Msondezi, male, 45 years)

For me, I prefer a woman to be my ideal foundation phase teacher because growing up we were socialised that men provide for the family and women take care of children. In our culture, women take care of children and men work. Conversely, since democracy, there is gender equality and men can work with children maybe as positive role models; but I do not see men teaching in foundation phase nowmaybe in the future. (Siyanda, male, 59 years) 

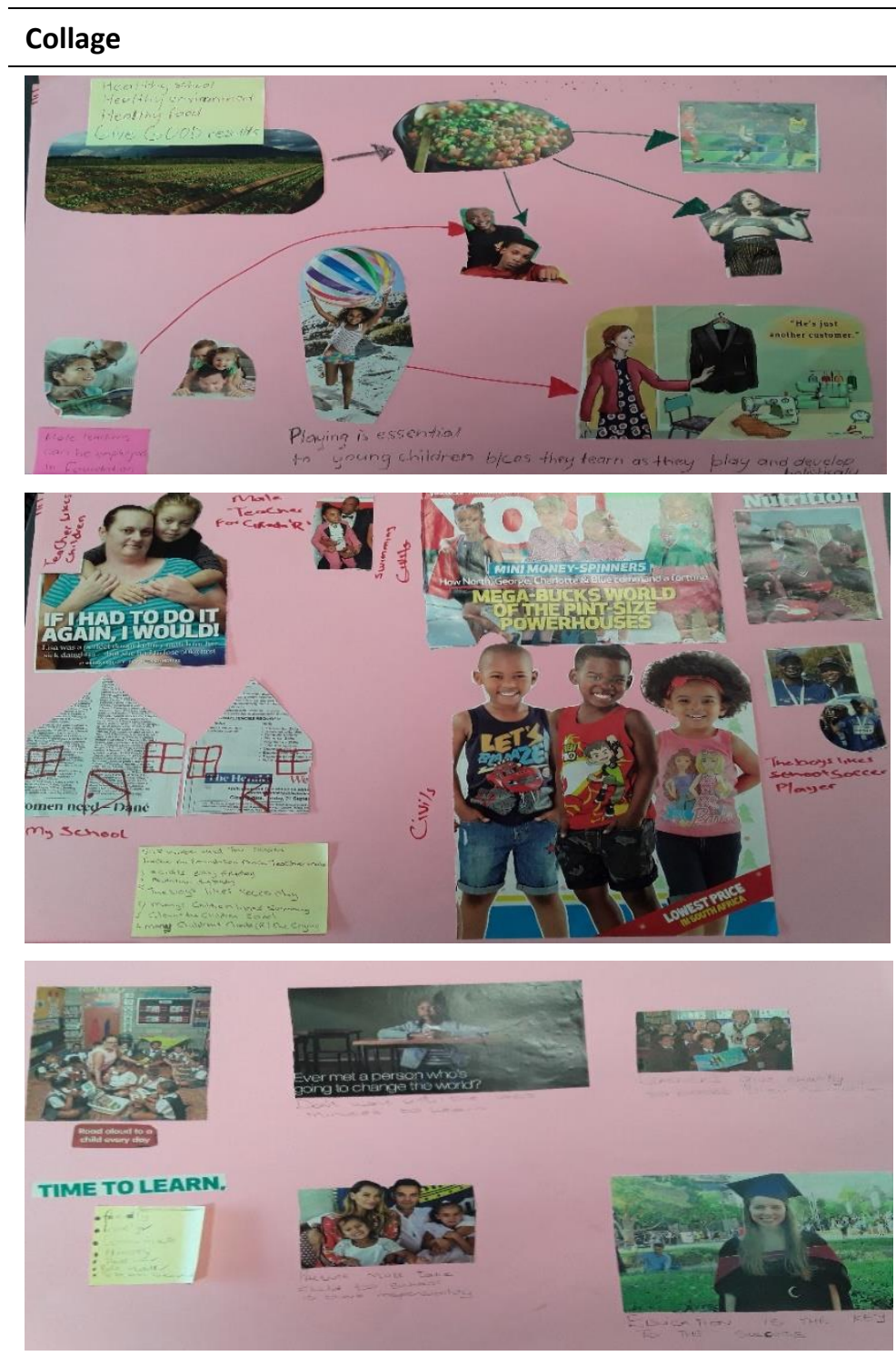

What do the collages mean?

I believe that my ideal foundation phase teacher should provide an environment that is positive and healthy for children, everyone can teach in foundation phase, male and female, so that children who do not have fathers or mothers could have role models. (Thembeka, female, 49 years)

My ideal foundation phase teacher should be a male teacher to teach sports (soccer and swimming), be a role model to the boy child and a disciplinarian to our children. (Zikhona, female, 45 years)

My ideal foundation phase teacher [she] should be friendly, loving, communicate, honest, hands-on and to be open to children. Mainly women are generally good at caring for children; she is soft and caring. (Bongiwe, female, 37 years) 


\section{Theme One: "Male FP teachers in My School? No, No, No!”}

Each participant in this study presented their collage to the rest of the group as outlined in Table 1 . In this section, we start with participants' conversation on what they saw and how they constructed meaning from their conversation. Bongiwe, Msondezi, and Siyanda aligned themselves with the feminised notion of FP teaching as rationalised in their captions:

Bongiwe: My ideal foundation phase teacher [she] should be friendly, loving, communicate, honest, hands-on and to be open to children. Mainly women are generally good at caring for children; she is soft and caring.

Msondezi: It is their responsibility and it is in their nature to take care of children. Men manage schools because they are disciplinarians.

Siyanda: That's why I say, this is a history issue because in our culture before, a woman was not supposed to work; she was supposed to look after the children, so the men go to work ... in our culture women take care of children and men work.

This discussion shows how these SGB members constructed their ideal FP teacher as feminine and nurturing, while arguing that men are not disposed towards a caring nature (Bhana, 2016; Ratele, 2015). However, during the discussion Thembeka presented a different view to the other three participants. She pointed out:

As you can see this is not a parent, this is a male teacher. This teacher, he reminds me of my father, I used to play with him so much and I really learned a lot from him. . . . I sometimes use the conversations we had to advise my own sons.

Thembeka's different viewpoint to FP teaching was not taken well by Siyanda and Msondezi. They argued:

Siyanda: Sorry, what were you saying? A male teacher in a foundation phase class? . . No, foundation phase is good for the mamas [women]. For sports and coaching, that I see, but not to teach! Men are abusive and impatient. Male foundation phase teachers, in my school? No, no, no, my friend. Not in the school while I am still SGB chairperson; even principal will never allow this.

Msondezi: I really do not see men being teachers of foundation phase, first thing is that the latches [lashes/punishment] of a woman is lesser than the latches or the harshness. Let's talk about the harshness. Men are too harsh than a woman, let's face the facts. Even in the pictures, we have more women than men.... That's why I say, this is a history issue because in our culture before, a woman was not supposed to work; she was supposed to look after the children, so the men go to work ... in our culture women take care of children and men work.

Siyanda and Msondezi's positioning of teachers in the context of FP teaching constructs men to be abusive, impatient, and harsh disciplinarians. This kind of positioning promotes hegemonic patriarchal forms of masculinities that subject women to subordinate forms of being and gender roles. Moosa and Bhana (2018), Ratele (2015), and Msiza (2019) argued in their studies that we need to encourage conversations and research initiatives on how to deconstruct the current hegemonic forms of masculinity among South African men. As the discussion by the participants ventured into what was missing in the collages made, the following ensued: 
Bongiwe: I see women as suitable for teaching the young ones. There are many women in our collages because they are soft ... they can take care of children.

Zikhona: For me, a well-behaved teacher can be someone who knows how to do his job and is qualified for it, man or woman.

Thembeka: Mmm ... flexible and accessible to the children ... also loving. FP has many women and no men. I prefer men ... they are very flexible with children.

Siyanda: A teacher for young children should show motherly love, be respectful and nice with children. That is why we see many women teaching the young ones.

Msondezi: Men manage schools because they are disciplinarians ... they cannot teach young children.

The participants were aware that most of their depictions were of female teachers. Despite this, some of them were still arguing that men were not suitable for teaching young children. Only Zikhona and Thembeka were positive about men teaching in the foundation phase. The argument raised by the three participants is in line with dominant discourses surrounding FP teaching. As argued by Osgood (2012), people in positions of power in a discourse create rules and regulations to maintain a specific order in a community and, eventually, these become norms or cultural practices. Thus, the legitimation of FP teaching as a feminine space has been passed on through rules and regulations in South Africa.

Bongiwe, Msondezi, and Siyanda naturalised care work as a normal duty for women and not as a reputable profession for both women and men. They ascribed the "manager and disciplinarian" roles to men, thereby positioning them as dominant in the hierarchy of employment. In support of his subordinate positioning of women, Msondezi stated: "A woman is the neck. So, in our minds we still have that perception and, we put that into practice, and culture gives more powers on that practice." Msondezi's statement portrays the patriarchal construction of womanhood that still exists in societies, including that of the amaXhosa. Therefore, the notion of women being the neck and men being the head has shaped how these participants view men as managers and disciplinarians, and women as caregivers to children. This form of subordination is also reflected in Msiza's (2019) findings where men were appointed for managerial positions because of their maleness and not their ability to manage and lead. Therefore, Moosa and Bhana, (2018) believed, men interested in teaching in FP should not be employed only to become managers and disciplinarians because this re-emasculates FP teaching; they believed that male teachers should be employed for their ability to teach and care for young children.

When Zikhona and Thembeka continued their conversation regarding their choice of men in FP teaching, the other three SGB members began to see things differently.

Zikhona: There are many children growing up without fathers. How about them? The male teacher can be a role model for the boys in school ... not all men are harsh too.

Thembeka: My father was very strict, but he was also very good for us. . . . he loved his children very much. Male teachers can also love children while being also strict ... uhm ... like discipline them.

Siyanda: Maybe in future when there will be a vacancy or post occurred at school, we won't only be blinded looking only for a female teacher. Because of this discussion today, 
of this workshop, of this training today, it opened our eyes, you see? And then, take that thing out of female dominancy in the foundation phase.

Bongiwe: I was going to say, yes, if there could be one male with the required qualifications for foundation phase, he can be hired. Since he is trained to be a foundation phase teacher, he can work for the learners, but he must be friendly to the kids. He must be able to communicate with them and have a love for kids.

While Siyanda and Bongiwe were warming to the idea of men teaching in FP, Msondezi still had a negative view:

Msondezi: Excuse me ... teaching is not simple. Our kids are quite naughty, more especially these small ones my brother. Let's say the women have patience but men are usually hungover on Monday. ... Because a male teacher, even the parents won't be happy. You can talk about other schools, but not my school. As the chairman of the SGB of School X, I say "No, no, no ... I d don't want you."

Pitsoe and Letseka (2013) argued that people use their experiences to construct and imagine the future. Thembeka did not have any experience of being taught by a male teacher in her primary school days but she relied on her lived experiences with her father. Zikhona's views on the need for male FP teachers was also based on her positive experiences with her father and on the absence of fathers in many children's lives. Pitsoe and Letseka (2013) posited that in conversations that tend to shift, deconstruct, or reimagine what is societally or historically regarded as normal, a different kind of thinking emerges and creates space for a changing discourse. From the conversation above, it is visible that a move towards a shifting of minds and the construction of a different discourse is possible. Bongiwe and Siyanda became open to possibilities of rethinking their approach to employment of men in FP. However, there is need to acknowledge that change is unsettling, and it takes time for people to adjust-as in the case of Msondezi.

\section{Theme Two: Male Teachers Are More Playful and Explorative}

Despite the normative construction of how the other three SGB members perceived FP male teachers, Zikhona and Thembeka were the only ones who were positive about male teachers in FP from the beginning. Thembeka and Zikhona referred to the FP male teachers as "accessible, flexible, and explorative in their teaching practice" during the sharing of their collages. Their views are like those of Warin and Adriany (2017) who found that FP male teachers tended to incorporate additional ideas about the available resources, and encouraged children to explore activities themselves - with an emphasis on playfulness and experimentation.

Thembeka: The girl children become very attached to their fathers, that is natural, that is what we mustn't push away. I know it by myself, because I was too attached to my father ... I still say male teachers are accessible to the children ... you see this one on my collage he is accessible to the children ... he is flexible, this one.

Zikhona: The teacher should be a male teacher to teach sports (soccer and swimming), be a role model to the boy child and a disciplinarian to our children ... especially those growing up without fathers.

Even though Zikhona and Thembeka were positive about male teachers in FP teaching, they were still using the hegemonic construction of masculinity as an asset to FP. They talked about men teaching sports and being disciplinarians for children. However, as they tried to convince the other three about the suitability of men in FP they also transformed their own thinking. 
Siyanda: But the mamas can also teach sport ... maybe if they share teaching then they can also share the responsibilities ... like some mamas teaching sports and some men teaching the young ones?

Thembeka: Mmm ... maybe! Bhuti, you could be right! If they share the work, then our children can benefit more ... like in a real family with a father and mother.

Zikhona: Yes! That is what I was saying . . . like, if the children have no fathers at home, they can have a father and mother at school!

Msondezi: My brother, I hear what you say but, hai! It is difficult to accept a man teaching young children ... but, jah! The children can benefit ... I see that ... I understand.

Bongiwe: Yah! When I look at it like that, I think it can work . . like men and women sharing the work of teaching in FP. The young ones need a lot of love and discipline when they are young. Maybe men learn from women and women learn from men ... yah!

In this discussion, Msondezi voiced a positive outlook on men teaching in the foundation phase while also acknowledging that it is not easy to change long-held beliefs about masculinity, an encouraging indication of how the discussion had mellowed his opinions. All the participants agreed on shared responsibility of teaching FP to create a homelike school environment for children who needed such an environment. However, their belief in the traditional family of male and female parents left out other forms of families that abound in South Africa. This could be a result of their personal socialisation into hetero-patriarchal communities (Bhana, 2016). Another key issue that drove participants' agreement was the missing fathers in many children's lives. Some of the participants believed that men in FP could be positive role models to boys growing up without fathers.

Thembeka: You see, like the children growing up without fathers. ... Who is their role model? They copy negative behaviours like being in gangs ... male teachers can become role models for them.

Siyanda: Jah! My sister, you see, some men are not good! But if we get good ones in the school ... they can be the role models ... I agree with that ... mmm!

Bongiwe: Yes! Girls also need fathers. Sis Zikhona and Thembeka had good fathers who helped them become the women they are today ... jah! The young girls need male role models too I think.

However, Martino and Rezai Rashti (2012) posited that the involvement of men in FP teaching should not be premised on the concept of providing "male role models" but should rather be embedded in the de-gendering of FP to provide learners with teachers who complement one another in their pedagogical practices, thereby exposing learners to the best possible learning experience irrespective of their gender, race, and social background. Bhana (2016) and Ratele (2015) believed that working with men and boys is important in changing the normalised perception that men are not caring and are violent towards women and children. The transformation in the views of the participants of this study towards acceptance of men in FP teaching and shared responsibility aligns with Bhana and Ratele's arguments for male involvement. 


\section{Theme Three: "It Is Doable"}

When participants reflected on what was missing in their collages, they realised that deep-seated beliefs about different phenomena could be changed through dialogue. Their collages had depictions of either women or men as the ideal FP teacher-with none showing both in one collage. However, during the discussions, they realised that what they had always believed to be a fact about FP teaching could change for the betterment of the phase and its learners.

Msondezi: Having agreed and disagreed in this workshop ... I had my own old ways thinking about the jobs people do. In the many years I have been in the SGB, I have not attended a workshop that addresses issues of gender equality and the involvement of men in foundation phase teaching. . . I I think my way of making decision will change from now moving forward.

Bongiwe: I agree with Msondezi. ... Government should have more workshops like this that encourage us to think out of the box... our children need different things these days. We also need to change how we do things ... it is not easy ... but, jah!

Zikhona: I wish my other SGB members from my school could have attended this workshop or meeting. ... I enjoyed making the collages and it really made us think out of the box like Bongiwe said ... to think about bringing men to teach young children and be involved in their lives ... but I wish we can have more of them and invite other parents in my community.

Siyanda: Yes, I have learned a few things . . like this thing is new to us . . . men teaching in foundation phase... I think we need more of these meetings and our government should workshop us on such issues so that we can take out our discomfort and help each other in building safe schools.

Thembeka: Yhoo ... what a fun way to discuss and learn new things that we were not aware of! I always thought that men and women can teach in foundation phase . . I did not know that it is my responsibility as the SGB member to bring about diversity and human right in the school. ... Bongiwe you are right, at that SGB workshop we did not discuss such information.

These participants realised that they needed training on how to best carry out their duties as SGB members. They valued the freedom and fun provided by participatory and visual methodologies. As highlighted by Karlsson (2002), there is need for measures that prevent the reenactment of traditional stereotypes of race, class, and gender inequalities in order to bring about transformation and equality in education. SGBs as members of the broader community have social values, norms, and cultural stereotypes that they represent in their task of governing schools. The engagement of SGBs in participatory methodologies in this study proved to be one effective measure of addressing the issues raised by Karlsson (2002).

\section{Mapping a Way Forward}

This article focused on how SGB members' perceptions of male FP teachers could be changed in the context of the Eastern Cape province. The study focused on SGBs because they are given the task of promoting social justice and diversity in schools, despite their own historical or sociocultural backgrounds and lived experiences (Bush \& Glover, 2016; Republic of South Africa, 2011a). However, Barrett (2005) argued that people's lived experiences do have an influence on which discourse to promote within a context. To change people's views requires a different view to research. Having 
engaged with SGB participants, we realised the power of participatory methodologies to promote social change and to raise awareness. Mayaba and Wood (2015), as well as Mitchell et al. (2017), stated that participatory methodologies work as a tool for social change by empowering people from all walks of life to mobilise for social change. Participants in this study also asserted that collage making helped them to rethink their practices and how they support old ways of thinking and making decisions.

Gough and Whitehouse (2003) argued that discourses, shared cultural practices, and cultural narratives are produced through language practices. In agreement, Moosa and Bhana (2018) argued that such beliefs and institutional categorisations have continually been used to justify perceptions and to keep men away from teaching in the FP. Participants in this study were socialised through language to feminise FP teaching. However, engaging in a different discourse allowed for transformation in their thinking about employing men in FP teaching. As argued by Foucault (1978), knowledge is constructed through discourses, which, together with social practices, form power relations and subjectivity. Thus, these SGB members have constructed different discourses that will possibly affect their social practice in schools. Having done this study, we believe that engaging other education stakeholders in participatory and visual methods such as collages can help to transform oppressive practices and discourses.

\section{References}

Barrett, M. J. (2005). Making (some) sense of feminist poststructuralism in environmental education research and practice. Canadian Journal of Environmental Education (CJEE), 10(1), 79-93.

Bhana, D. (2009). "Boys will be boys": What do early childhood teachers have to do with it? Educational Review, 61(3), 327-339.

Bhana, D. (2016). Gender and childhood sexuality in primary school. Springer.

Bhana, D., \& Moosa, S. (2016). Failing to attract males in foundation phase teaching: An issue of masculinities. Gender and Education, 28(1), 1-19.

Blaise, M. (2005). Playing it straight: Uncovering gender discourses in the early childhood classroom. Routledge.

Brownhill, S. (2016). Male role models in education-based settings (0-8): An English perspective. In S. Brownhill, J. Warin, \& I. Wernersson (Eds.), Men, masculinities and teaching in the early childhood education: International perspective on gender and care (pp. 26-35). Routledge.

Burr, V. (1995). Overview: Realism, relativism, social constructionism and discourse. In I. Parker (Ed.), Social constructionism, discourse and realism (pp. 13-26). SAGE.

Bush, T., \& Glover, D. (2016). School leadership and management in South Africa: Findings from a systematic literature review. International Journal of Educational Management, 30(2), 211-231.

Carabine, J. (2001). Constituting sexuality through social policy: The case of lone motherhood between 1834 and today. Social \& Legal Studies, 10(3), 291-314.

Connell, R. (2012). Masculinity research and global change. Masculinities \& Social Change, 1(1), 4-18.

Creswell, J. W. (2013a). Qualitative inquiry \& research design (3rd ed.). SAGE.

Creswell, J. W. (2013b). Research design: Qualitative, quantitative, and mixed methods approaches. SAGE.

Cushman, P. (2005). Let's hear it from the males: Issues facing male primary school teachers. Teaching and Teacher Education, 21(3), 227-240. 
Cushman, P. (2008). So what exactly do you want? What principals mean when they say "male role model." Gender and Education, 20(2), 123-136.

Davies, L. (1999). Researching democratic understanding in primary school. Research in Education, 61(1), 39-48.

de Lange, N., Khau, M., \& Athiemoolam, L. (2013). Using participatory and visual arts-based methodologies to promote sustainable teaching and learning ecologies: Through the eyes of preservice teachers. TD: The Journal for Transdisciplinary Research in Southern Africa, 9(3), 401-412.

de Lange, N., Mitchell, C., Moletsane, R., Stuart, J., \& Buthelezi, T. (2006). Seeing with the body: Educators' representations of HIV and AIDS. Journal of Education, 38, 45-66.

Foucault, M. (1978). The history of sexuality: An introduction (Vol. 1, R. Hurley, Trans.). Random House.

Gough, A., \& Whitehouse, H. (2003). The "nature" of environmental education research from a feminist poststructuralist viewpoint. Canadian Journal of Environmental Education (CJEE), 8(1), 31-43.

Karlsson, J. (2002). The role of democratic governing bodies in South African schools. Comparative Education, 38(3), 327-336.

Martino, W., \& Rezai-Rashti, G. (2012). Rethinking the influence of male teachers: Investigating gendered and raced authority in an elementary school in Toronto. Review of Education, Pedagogy, and Cultural Studies, 34(5), 258-281.

Mashiya, N., Kok, L., Luthuli, N., Xulu, S., \& Mtshali, Z. (2015). Foregrounding the gender divides in early childhood teacher education: A case of South Africa. Journal of Social Science, 42(3), 259-265.

Mayaba, N., \& Wood, L. (2015). Using drawings and collages as data generation methods with children: Definitely not child's play. International Journal of Qualitative Methods, 14(5). 1609406915621407.

Merriam, S. B. (2009). Qualitative research (2nd ed.). Jossey-Bass.

Mfecane, S. (2016). "Ndiyindoda" [I am a man]: Theorising Xhosa masculinity. Anthropology Southern Africa, 39(3), 204-214.

Mitchell, C., \& de Lange, N. (2013). What can a teacher do with a cellphone? Using participatory visual research to speak back in addressing HIV\&AIDS. South African Journal of Education, 33(4), 1-13.

Mitchell, C., de Lange, N., \& Moletsane, R. (2017). Participatory visual methodologies: Social change, community and policy. SAGE.

Mncube, V., \& Mafora, P. (2013). School governing bodies in strengthening democracy and social justice: Parents as partners? The Anthropologist, 15(1), 13-23.

Mncube, V. (2009). The perceptions of parents of their role in the democratic governance of schools in South Africa, Are they on board? South African Journal of Education, 29(1), 83-103.

Moosa, S., \& Bhana, D. (2018). "They won't take you as a man, as a real man": Why men can't teach young children in foundation phase. International Journal of Inclusive Education, 22(6), 577-593.

Moosa, S., \& Bhana, D. (2020). Men teaching young children:"You can never be too sure what their intentions might be." Oxford Review of Education, 46(2), 169-184.

Msiza, V. (2019): "You are a male teacher, but you have a woman's heart": Foundation phase teachers negotiating identities in South Africa. Education 3-13, 48(6), 651-660.

Msiza, V. (2020). "I don't like them coming to me and saying hey, I like you": Male teachers in relegated positions of masculinity. Agenda, 1-8.

Ntombana, L. (2011). Should Xhosa male initiation be abolished? International Journal of Cultural Studies, 14(6), 631-640. 
Osgood, J. (2012). Narratives from the nursery: Negotiating professional identities in early childhood. Routledge.

Ostby, J. (2017). What are the experiences of family caregivers participating in an arts-based (collage) intervention? A secondary analysis [Unpublished doctoral dissertation]. University of Alberta, Canada.

Petersen, N. (2014). The "good," the "bad" and the "ugly"? Views on male teachers in foundation phase education. South African Journal of Education, 34(1), 1-13.

Pitsoe, V., \& Letseka, M. (2013). Foucault's discourse and power: Implications for instructionist classroom management. Open Journal of Philosophy, 3(1), 23-28.

Ponterotto, J. G. (2005). Qualitative research in counselling psychology: A primer on research paradigms and philosophy of science. Journal of Counselling Psychology, 52(2), 126-136.

Ratele, K. (2015). Working through resistance in engaging boys and men towards gender equality and progressive masculinities. Culture, Health \& Sexuality 17(2), 144-158.

Republic of South Africa (RSA). (2011a). South African Schools Act 84 of 1996. Government Printer.

Republic of South Africa (RSA) (2011b). The Educators Employment Act (Act 76 of 1998). Government Printer.

Scott, J. W. (1988). Deconstructing equality-versus-difference: Or, the uses of post-structuralist theory for feminism. Feminist Studies, 14(1), 33-50.

Skelton, C. (2012). Men teachers and the "feminised" primary school: A review of the literature. Educational Review, 64(1), 1-19.

Taylor, P. C., \& Medina, M. N. D. (2013). Educational research paradigms: From positivism to multiparadigmatic. Journal for Meaning-Centered Education, 1(1).

https://www.academia.edu/29954406/Educational Research Paradigms From Positivism to PI uralism

Tenge, S. (2006). Xhosa teenage boys' experience during the period prior to circumcision ritual in East London in the Eastern Cape province [Unpublished doctoral dissertation]. University of South Africa.

Unterhalter, E., \& North, A. (2011). Responding to the gender and education millennium development goals in South Africa and Kenya: Reflections on education rights, gender equality, capabilities and global justice. Compare: A Journal of Comparative and International Education, 41(4), 495-511.

Warin, J. (2019): Conceptualising the value of male practitioners in early childhood education and care: Gender balance or gender flexibility. Gender and Education. doi:10.1080/09540253.2017.1380172

Warin,J., \& Adriany, A. (2017). Gender flexible pedagogy in early childhood education. Journal of Gender Studies, 26(4), 375-386. doi:10.1080/09589236.2015.1105738

Weedon, C. (1997). Feminist practice \& poststructuralist theory. Blackwell.

Weedon, C. (2004). Identity and culture: Narratives of difference and belonging: Narratives of difference and belonging. McGraw-Hill.

Xu, Y., \& Waniganayake, M. (2018). An exploratory study of gender and male teachers in early childhood education and care centres in China. Compare: A Journal of Comparative and International Education, 48(4), 518-534. 